\title{
The Collective Magic of Community Action: a Review of William Mazzarella's The Mana of Mass Society
}

The University of Chicago Press; ISBN 9780226436258; 224pp; Paperback $\$ 25.00$ Jo Richardson

Around one hundred years ago, the world of anthropology was having a 'Mana' moment. Durkheim had established the field of sociology with his (1895) Rules of Social Method (Durkheim, 1982) and academics were attempting to structure sense and meaning, in order to better understand collective thought and action in society. A little bit of magic was required to do this. European explorers and religious missionaries had seen a mystical force at work in the collective rituals of Indigenous communities. Sahlins (1976) refers to Moalan tradition where 'Mana' was defined as 'male potency' (pg 26) which, during rituals, worked its effect through objects and totems that had a mystical power. Words used to describe 'Mana' in a range of texts, refer to 'energy' and 'effervescence' in a collective, drawing from an originating, mystical source of potent power. Illustrative drawings of such rituals, in some of the anthropological texts of the time show a sort of collective, ecstatic transcendence, with each member of the group in and beyond themselves, connected but absorbed.

'Mana' was fascinating to those looking for a theory to explain collective and contagious moments of crowd power, at that time. However, it was discredited by the middle of the last century - chief among its faults was the, seemingly context-specific, idea of 'Mana' could be taken and transplanted to explain structure in Western societies. This magic notion was appealing, but its sleight of hand had been revealed. The process of applying a Western global eye to the 'magical' cultural traditions of community transcendence through the collective, was discredited as a stretch too far.

The pulsating lights and beats of the Chemical Brothers set at Glastonbury 2019 brought 'Mana' to mind for me. Having read Mazzarella's theory (2017) The Mana of Mass Society and attempted to make sense of it through application to my own area of social housing research, it was a musical moment which helped. Through the television, the lights on stage at Glastonbury connected with the 'smart' lights in the room at home, the volume loud, the musical and heart beats pulsing, I was there and apart at the same time - watching the festival-goers move and interact as one - transformed by the lights and the music into one body - immanence and transcendence seemingly at once. There was I, looking on through the screen, but through the speakers and the lights connected to that part of Somerset, echoing colour changes there to here, part of the transformed, pulsating collective body of experience. Until that moment, I had been struggling with Mazzarella's 'Mana' in its abstractness, but in that musical moment, it seemed 'Mana' might be a feeling, with all the complexities of definition that apply to human emotions.

Turning back a century, to a time when the anthropological construct of 'Mana' was in its heyday, is a bold move for Mazzarella. He refers to 'Mana' as a 'recurrent symptom' and looks to 'redeem' this frame of understanding from its exile (pg 170). In the first half of the book, particularly, Mazzarella weaves in and out of historical texts and ideas of 'Mana' to attempt to elucidate it as a theory which can be applied to 'mass society' today to understand, for example, advertising and mass politics. 
'As I thought and wrote, I watched 'that mana wave called Trump' morph from improbable to inevitable and back...and back again' (Mazzarella, 2017, pg 2)

The narrative from Mazzarella reveals a complex and at times impenetrable, circular definition of magical 'Mana'. For further clarity, turning back further to Mauss' (1950) General Theory of Magic, 'Mana' is explained as 'troublesome', 'curious' and 'vague', but 'curiously definite' (Mauss, 2001, pg 134). Mauss provided three elements of 'Mana' firstly he offered it as a 'quality' (something which possesses the 'thing' of 'Mana'), secondly as 'the thing', and thirdly as a 'spirit' (souls of ancestors and forces of nature) (pgs 134-5). Fundamentally, Mauss suggested that 'magic' is a social phenomenon and 'Mana' is the expression of that (pg 150). In its geographical and temporal context, the magic of 'Mana' was a way to understand the collective, interactive rituals of tribes and communities which result in an ethereal feeling of something larger than its individual constituent parts. It must have been tempting, a century ago, to apply this to the energy and collective action of crowds in the Western world, but should it tempt us again now?

Mazzarella suggests that 'Mana' in its order and excess is seen in political speech, advertising and art. Mass hypnosis, and political frenzy as seen in present day responses to 'Trumpism'. But, can we really bring Mana to the present, to explain the collective forces of $21^{\text {st }}$ Century society, such as Trump, Brexit, Boris and more prosaic consumer crazes, seemingly driven by the energy of crowds? Or are there other explanations? In physical interaction, explanations (Goffman, 1967) on the physiological responses between human beings can be seen to create an effervescent response for a moment - the encounter passes but affects a relationship between the people in the encounter. This encounter is: '...one of the ways in which social contacts are geared into the wider society'. (Goffman, 1967, pg 41)

For Mazzarella, Mana is not binary, moreover the processes which gear Mana into society can be seen as '... social dialectic between historically layered, sensuously resonant potentials...' (pg 147). In the abstract, it is difficult to bring to life the physicality of the layered effects of Mana. I looked to Collins (2004) for practical detail of the physical patterns of movement that occur during interaction that demonstrates a measure of 'collective effervescence':

'At peak moments the pattern tends to be jointly shared among all participants: in high solidarity moments, bodies touch, eyes are aligned in the same direction, movements are rhythmically synchronized'. (Collins, 2004 pg 135)

This synchronization can happen in face-face encounters, or larger crowds. It can produce an energy which can be 'good' or 'bad'; but Mazzarella makes clear in his work - that Mana is not good or ill, it is not so binary. Mana may be 'amoral', but the effects have consequences - winners and losers - just like the cooperation used for the 'amoral purpose of successful competition' seen in the natural world (Greene, 2013, pg 353). Indeed, Haidt (2012) suggests that, whether on an individual level or in a wider group, in the effervescence of competition, there is an integral 'self-interest' at play that we utilise 'mental mechanisms' to promote 'our group's interests, in competition with other groups'. (Haidt, 2012 pg 231). Moreover, Nussbaum (2013) in her discussion on public emotions in collective effervescence, further outlines the longer-term potential malign effect of collective action, and that the large-scale public consequences may result in 
hardened lines of conflict and hierarchy: '...introducing or reinforcing divisions, hierarchies, and forms of neglect or obtuseness.' (Nussbaum, 2013, pg 2). Consequently, whilst Mana as a method of public effervescence, itself may not be binary 'good' or 'evil', the effects on society, particularly on already marginalised groups, may not be so amoral.

In his work, Mazarella wagers that analysis of three Mana 'settlements' - empiricist (contextualised in place and moment), primitive (features of primitive collectives and their collective identity, apart from 'civilised' individuals) and aesthetic (resonant encounters with an object (e.g. art) which makes us subject) - will open new ways of thinking. By 'settlement' Mazzarella says he means: ... the tension between the appearance of a negotiated, reasonable compromise and the violence of the settler... (pg $10)$ - that moment of compromised peace, before the disruptive shift in discourse.

Mazzarella is interested in the interplay between the macro-level collective energy, and the micro-level experience and he says that it is important to explore 'the relationship between the exceptional and the everyday' (pg 3). Other writers have referred to this 'between' as a 'hinge':

'Things go sideways. Anything can start to act like a hinge, activating something suddenly somehow at hand. Forms piggyback on each other'. (Berlant and Stewart, 2019, pg 22)

But, Mazzarella's (2017) book offers abstract theoretical reflections on a potential resurgence for 'Mana', and does not explore practical examples of such 'hinges' or moments of mass politics, mass media, mass advertising in order to provide a deeper understanding of the relevance of Mana today. Mazzarella suggests that he has 'staged a series of resonant encounters between past and present, between anthropology and critical theory, between assertion and speculation' (pg 171). As a stage, this is an interesting and thought-provoking work, (particularly in reflection on my own study of the performative element of 'home', Richardson, 2019), but I was looking for modern day actors to inhabit the stage. As an 'applied' researcher, I was looking for practically applicable clues for understanding mass moments in the modern context, but did not find them. I could see the temptation in 'Mana' as an explanation for the Brexit referendum, for the election of Trump, but it was a leap without examples of evidence from field research. I was taken with Mazzarella's seductive power of 'Mana', explained as 'the chocolate side of power' (pg 165), but, as with chocolate - I wanted one more piece.

In the social science field of housing and homelessness, I sought my own potential realms for exploration. One hundred years ago, in the same period as the 'Mana' moment in anthropology, we saw the passing of the Addison Act - a precursor to mass house-building by the state, on a scale not seen in housing policy before or since. The collective effervescence of the post-war period, and the concern for men returning from battle, along with health evidence that slum-dwelling in cities was counter to public health and wellbeing, created a moment where the vision of providing homes was a collective dream. This magic moment passed, and has not been seen since. The inclusion of council or social housing in plans today, causes objection from housebuilder and settled communities alike - it is seen as unpopular and unviable. Politicians 
understand how to capitalise on this collective objection and use 'dogwhistle' discourse which taps into the collective psyche and resonates the worst fears through political speech. For marginalised communities, such as Roma, Gypsies and Travellers this is further compounded by collective fear and distrust manifested in hostile words and actions (Richardson 2017, Richardson and Ryder 2012). We see this also in the reflection of Trump's words of 'send them back' in pictures of drowned Mexican immigrants, and daily mass shootings in the U.S.A.

The use of social media as a virtual bubble of collective effervescence can turn words into hostile vigilante action to move people on from a place, or to prevent them stopping for a while. If this is 'Mana' magic at work, it is has a dark underside. It may be able to offer, through use of 'totem' as 'brand', a way of re-positioning the image of, say, Gypsies and Travellers in popular understanding. If 'Mana' of mass society, is seen in marketing and the contagion of ideas, then it may be possible to apply fresh understanding of this theory in ways to benefit marginalised and misunderstood communities. The 'totem' of the caravan, that does not resonate in wider culture and can set Gypsies and Travellers apart, could be framed within an understanding of 'Mana' as an attempt to reframe. 'Mana' creates and constitutes the awareness of the Gypsy/Traveller group - making and unmaking of meaning in mass mediated contexts. The totem might be a point of traction in debate, as a point of fixity for a period of time, for the purpose of positive reframing.

'Mana', in all three of its 'settlements', can be seen as socially constructed 'empty signifiers' ready to be defined and re-defined in moments. Laclau and Mouffe (2001) suggest that signifiers (and any solid meaning of things) can only ever be partially fixed because the field of discursivity (the context for the debate) is constantly changing and overwhelming any momentary understanding of what a particular node (thing, person, group, 'Mana') is. An attempt to fix meaning is overwhelmed by new information and by wider reactions to attempts to fix meaning. This changing discourse which overflows partially fixed meanings of social identity can be seen to occur not just in the external debate which socially constructs and re-constructs identities (e.g. the debate about Gypsies and Travellers by public, press and politicians) but also the internal debate within and between groups themselves. 'Mana' may be one mystical part of the ingredients at play in fixing and re-fixing meaning in moments, but there are other tangible explanations too.

In his stark imaginings for the future, Harari (2016) refers to 'Dataism' as a new form of collective identity - going beyond the organic constitution of Homo Sapiens but further subject to the non-human power of the algorithm.

'The cosmic data-processing system would be like God. It will be everywhere and will control everything, and humans are destined to merge into it. This conception is reminiscent of some traditional religious visions'. (Harari, 2016, pg 444)

These algorithms, seen in the Cambridge Analytica scandal around the Brexit referendum and the Trump election, take on a magic 'Mana' effervescence of their own, with humanity disaggregated into series of data bytes morphing together to create new online communities of knowledge - the scale of which shows elements of us that we did not even know ourselves. In the (2019) documentary film, The Greatest Hack, the scale 
of collective data (based on thousands and thousands of data points per person) allowed whole communities to be 'persuaded' by arguments targeted at each individual's distinct personality, through the 'bloodstream of the internet'. Knowledge from mass data was used in politics of hate and fear in the Brexit and Trump campaigns, not to bring people together in a 'Mana' moment, but to divide and rule. In the (2019) documentary film, one Cambridge Analytica witness told the UK Parliamentary Select Committee investigating the issue, that such data communication was judged by the military as 'weapons grade'.

Mazzarella's (2017) 'Mana' discusses resonant, constitutive encounters, where moments become more vividly themselves through an encounter with each other. In his interview to explain the book (Oliphant, 2018) Mazzarella suggests that his work offers theoretical interpretation to 'redeem' 'Mana' for today, and he also suggests it offers 'method' but acknowledges this might not be so readily apparent. There is an interestingly constructed framework for consideration here in 'Mana' and it is a useful contribution, particularly in exploration of research with communities who have totemic heritage in their culture (or 'mimetic archive' as Mazzarella would define it). As a framework to explore the collective 'effervescence' of crowds, this could be a helpful tool, for example, in understanding the contagion of objection in planning for social housing, or Traveller sites - what are the moments that gain traction from public collective consciousness and how can those social ingredients be used to reframe a negative collective debate into a more positive collective conversation?

'Mana of Mass Society' might not explain the hysteria of contagious online debates, but it is a thought-provoking construct in which to question our current collective resonance and to consider other-worldly ways of understanding Brexit and Trumpian moments in modern political society. However, it is an exercise in circular argument that does not fully redeem the relevance of Mana for today. At the start of his book, Mazzarella suggests that his work is not quite a manifesto, but an exercise in 'dialectical vitalism'. He refers to previous friendly criticism of his approach that he 'wanted to have it both ways' and says "On that score I remain unrepentant, if anything more insistent than ever" (pg 14). In using both vehicles of ethnographic theory and critical theory, Mazzarella offers 'Mana' as a framework for questions on society today, but perhaps in 'having it both ways' does not fully offer illumination or redemption -for 'Mana' as the vital lens of explanation for our modern, global world.

\section{$\underline{\text { References }}$}

Berlant, L and Stewart, K (2019) The Hundreds, London: Duke University Press Collins, R (2004) Interaction Ritual Chains, New Jersey: Princeton University Press Durkheim, E (1982) The Rules of Sociological Method, translation from the original (1895), New York: Simon \& Schuster

Evans, J (2015) 'Can governments create 'collective effervescence' in their citizens? And should they? The History of Emotions Blog, March 20 th 2015, www.qmul.ac.uk/emotions Goffman, E (1967) Interaction Ritual: Essays on Face-to-Face Behaviour, New York: Pantheon Books

Greene, J (2013) Moral Tribes: Emotion, Reason and the Gap Between Us and Them, London: Atlantic Books 
Haidt, J (2012) The Righteous Mind: Why Good People are Divided by Politics and Religion, London: Penguin Books

Harari, Y.N, (2016) Homo Deus: A Brief History of Tomorrow, London: Penguin Random House

Laclau, E and Mouffe, C (2001) Hegemony and Socialist Strategy, towards a radical democratic politics ( $2^{\text {nd }}$ ed) London: Verso

Liebst, L.S (2019) 'Exploring the Sources of Collective Effervescence: A Multilevel Study' Sociological Science 6: 27-42

Mauss, M (2001) A General Theory of Magic, London: Routledge Classics

Netflix (2019) The Greatest Hack, Documentary film, Netflix

Nussbaum, M (2013) Why Love Maters for Justice, Boston, Belknap Press

Oliphant, E (2018) 'William Mazzarella on his new book, The Mana of Mass Society', CaMP Anthropology, online https://campanthropology.org/2018/07/16/williammazzarella-the-mana-of-mass-society/

Richardson, J and Ryder, A (Eds) (2012) Gypsies and Travellers: Empowerment and Inclusion in British Society, Bristol: Policy Press

Richardson, J (2017) 'Precarious living in liminal spaces: neglect of the Gypsy-Traveller site'. Global Discourses, Volume 7, pp 496-515

Richardson, J (2019) Place and Identity: The Performance of Home, Abingdon: Routledge Sahlins, M (1976) Culture and Practical Reason, London: The University of Chicago Press 